\title{
魚肉中のアミンの生成について一VII. 解凍魚肉中のヒスタミンの生成に対する凍結の影響
}

\author{
太田冬雄・金子弘助 \\ (鹿児島大学水産学部)
}

\author{
On the Formation of Amine in Fish Muscle-VII. \\ -Effect of Freezing on the Histamine Formation in the \\ Thawed Fish Muscle-
}

Fuyuo Ota and Kosuke Kaneko

\begin{abstract}
The histamine formation in the thawed fish muscle, which had been kept in the frozen state under various conditions, was examined. It was found that appearance of histamine was delayed and depressed in the thawed muscle, whereas no appreciable difference between the thawed and fresh muscles was observed in the course of deterioration judged by the increase of ammonia and mercuric chloride reaction. The depression effect of freezing varied according to the storage period or temperature, and little histamine was produced in the fish thawed after being frozen for long time or at a lower temperature (Figs. 1, 2 and 3).

As the inoculation of spoiled fish muscle (suspension) resulted in the accerelation of histamine formation in the thawed muscle to the level observed on the fresh muscle, the depression effect may be attributable to the destruction of histamine producing-bacteria by low temperature (Figs. 4 and 5).
\end{abstract}

一般に，冷凍魚の解凍後の保存性は生魚よりる低いと考克られがちである。それは，凍結によつて焦肉の 性状が変化するため，微生物その他の侵入，作用を受け易いと考光られるからである。しかし，従来の結果 によると必らずしもそうではなく，解凍魚の自己消化及び腐敗の速度は，凍結，解凍の条件が適当であれば

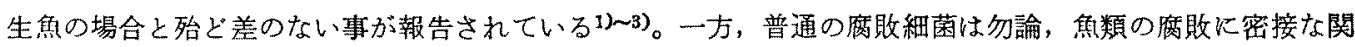
係をるつ海水細菌も寒冷細菌ではあるが4， ある程度の低温比放置されるとかなりの量が死隇する事が報告 されているす) 。)。

しかも，魚肉中のヒスタミンを生成する細菌は，普通の腐敗菌と異なる若干の海水炕由来する細菌による といわれる7から，解凍魚の鮮度低下，腐敗に上るヒスタミンの生成が，どの様な变化を示すかは，解涷魚 の保存性を食品壋生上から考える上に，又，ヒスタミン生成菌の耐寒性を知るためにる重要な事であると思

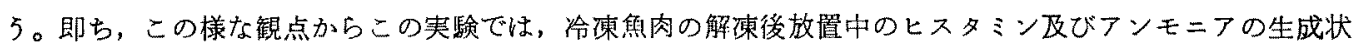
沉と、これと対する冷凍条件の影響についてしらべた。

\section{実験}

万 法

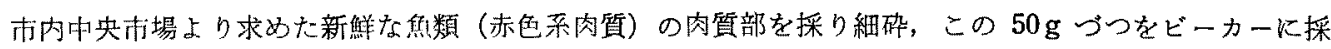
りパラフイン紙で抬和つたもの所要数を用意し，その中の1ケは対照区としてそのまま $20^{\circ} \mathrm{C}$ の恒温器中に 放置し，肉質中のヒスタミン $(\mathrm{Hm})$ 及びフンモニフ $(\mathrm{Am})$ 量の変化を測定，他は 2 ケづつを 1 区分として

1958 年 1 月 10 日受理

* 本報の要旨は, 日本水産学会（東京，1955，4）にて発表した。 
当学部内実習工場冷藏連の温度の異なる 3 室 (A. $-5 \sim-9^{\circ} \mathrm{C} ;$ B. $-10 \sim-16^{\circ} \mathrm{C} ; \mathrm{C},-16 \sim-21^{\circ} \mathrm{C}$ ) K

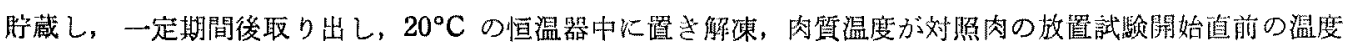
（室温々同一乙看做した）に達した時を放置開始点として，そのまま放置し肉質中の $\mathrm{Hm}$ 及び Am 昷の変化 を測定, 対照区の变化と対比した。尤も，凍結肉の場合，凍結状態のものは問題ないとしても，凍結される までと解凍後上述の放圆形始点の温度に達するまでの間には，当然多少なりとも腐敗その他の変化の行われ ている事が考党られるから，対照区との比較条件としては少しく疑義があると思われるが，問題になる時間

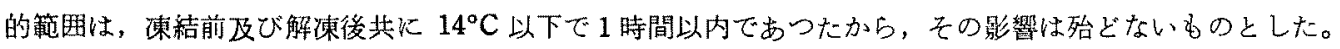

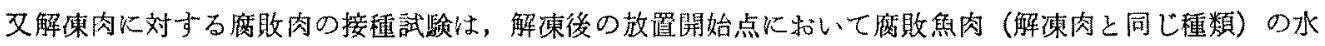

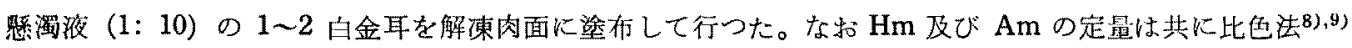

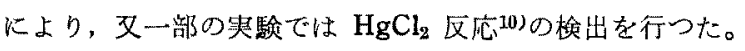

\section{結 果}

\section{1. 凍結貯藏期間の影響}

サバ肉を用い，A，B，Cの各室に 11 日か576 日間凍結舵蔵した場合の結果をFig. 1 に示した。図に 見られる様に, Am の生成は対照区のものが多少速く, 他は冷凍条件に上つて腐敗期以後は, 詝蔵温度が低 く，且つ眝藏期間の長い程緩漫な様に見方る。しかしこれらの差はそれ程大きいものとは認め難い。又この 間の $\mathrm{HgCl}_{2}$ 反応に上る初期腐敗期は凍結区の方が刘照上りも多少括くれて観察された。しかるに，Hmの 変化は各区分で著しく相異し，凍結したものはいずれも対照上り生成の開始が括くれ，且つ生成量も少なく 更に凍結詝蔵期間が長くなるにつれて生成が少なくなり，76 日詝蔵のものではいずれの温度に貯蔵したもの も, $\mathrm{Hm}$ は殆ど全く生成されなかつた。

これらの傾向はマイワシについての結果 (Fig. 2) からも明らかで, Hm については全く同様の事がいわ
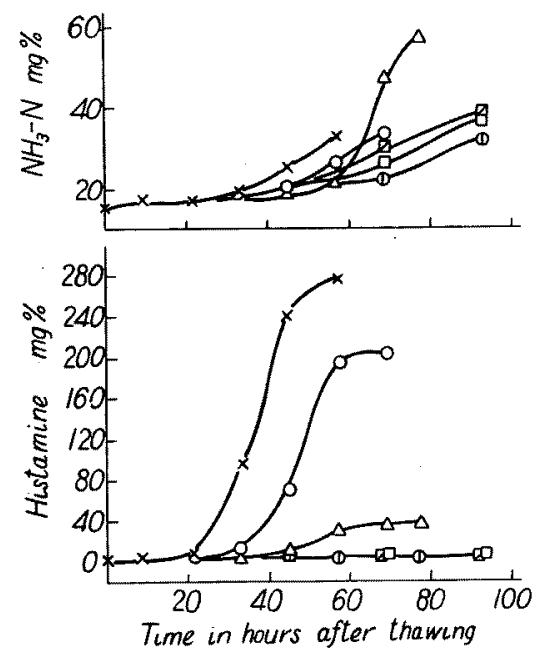

Fig. 1. Formation of histamine and ammonia in the thawed mackerel muscle, which has been kept in frozen state under various conditions.

$x$, unfrozen (control); $\bigcirc$, forzen and kept at $-16 \sim-21^{\circ} \mathrm{C}$ for 11 days; $\triangle$, at $-10 \sim-16^{\circ} \mathrm{C}$ for 25 days; $\square$, at $-16 \sim-21^{\circ} \mathrm{C}$ for 76 days; $(D$, at $-10 \sim-16^{\circ} \mathrm{C}$ for 76 days; $\square$, at -5 $\sim-9^{\circ} \mathrm{C}$ for 76 days.
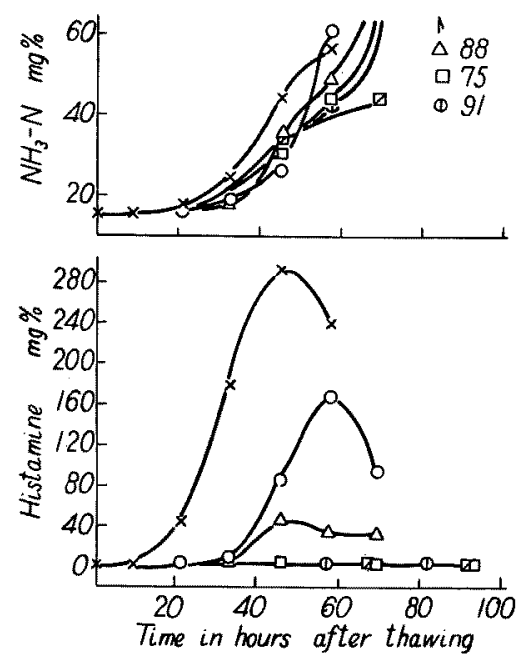

Fig. 2. Formation of histamine and ammonia in the thawed sardine muscle, which has been kept in frozen state under various conditions.

$x$, unfrozen (control); $\bigcirc$, frozen and kept at $-16 \sim-21^{\circ} \mathrm{C}$ for 11 days; $\triangle$, at $-10 \sim-16^{\circ} \mathrm{C}$ for 25 days; $\square$, $-16 \sim-21^{\circ} \mathrm{C}$ for 76 days; (D), at -10 $\sim-16^{\circ} \mathrm{C}$ for 76 days; $\square,-5 \sim-9^{\circ} \mathrm{C}$ for 76 days. 

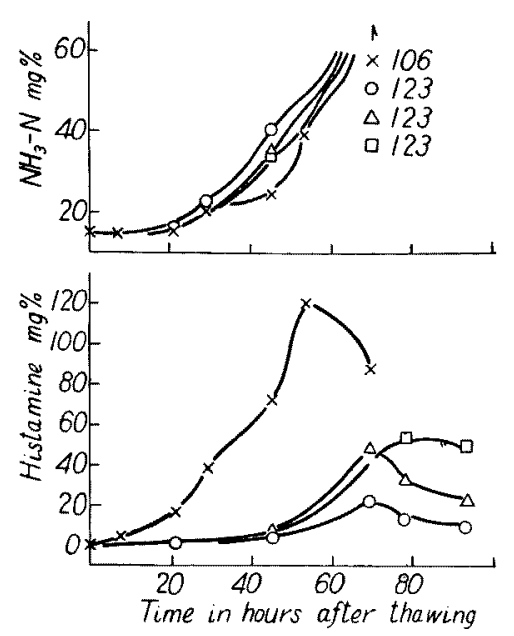

Fig. 3. Formation of histamine and ammonia in the thawed muscle of round herring, which has been kept in forzen state at different temperatures for 42 days.

$x$, unfrozen (control); $\supset$, frozen and kept at $-16 \sim-21^{\circ} \mathrm{C} ; \triangle$, at $-10 \sim$ $-16^{\circ} \mathrm{C} ; \square$, at $-5 \sim-9^{\circ} \mathrm{C}$.
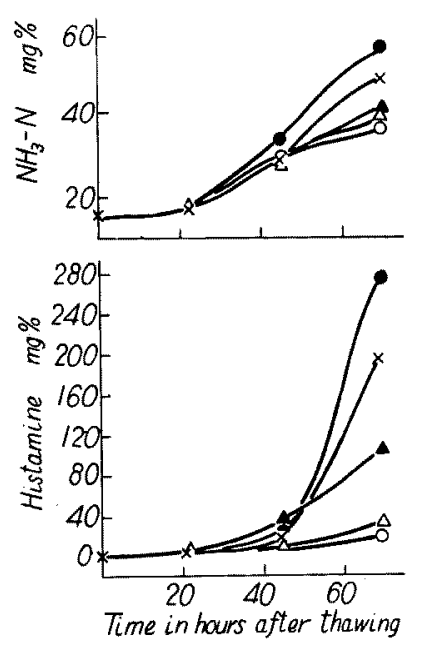

Fig. 4. Accerelation of histamine formation by the inoculation of spoiled fish muscle to the thawed mackerel muscle.

$x$, unfrozen; $O$, frozen and kept at $-16 \sim-21^{\circ} \mathrm{C}$ for 50 days; $\bullet$, at $-16 \sim-21^{\circ} \mathrm{C}$ for 50 days (inoculated) ; $\triangle$, at $-10 \sim-16^{\circ} \mathrm{C}$ for 50 days; $\wedge$, at $-10 \sim-16^{\circ} \mathrm{C}$ for 50 days (inoculated).

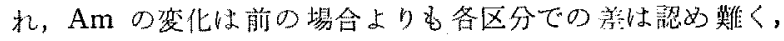
$\mathrm{HgCl}_{2}$ 沌応と垬にいずれも站ど同様の変化を示した。即も湅結 処理が明らが $\mathrm{Hm}$ の生成に刘し抑制作用を示している。

\section{2. 凍結眝蔵温度の影響}

前項の結果では，貯減温度の影響が明らかでないので，ウル メイワシを用い各室に 42 日間凍結腚蔵しこの点をしらべた。 气の結果が Fig. 3 で, Am の生成は, むしろ対照が淶結区よ りも幾分少なく見党るのに対し，Hmのそれは前項の結果と同 棣凍結区のものがいずれも少なく，乙かる眝藏温度の低い程少 なかつた。これらの傾向は, サバについての同様の試験結果か らも明らかであつた(図省略)。 $\mathrm{HgCl}_{2}$ 区応に上る涑結区の初 期腐敗は，イワシの場合対照より多少早められ，サバでは多少 志くれて観察された。

以上の結果から，凍結処理怔解凍肉放置中の Am の生成に 対しては殆ど影艮はないが，Hmの生成に刘しては阻害的影響 を与えている事が確实である。ここで，实䮖方法の項で述べた

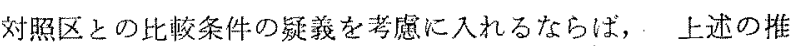

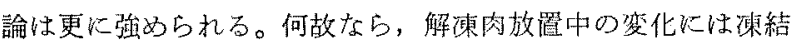
前及び解瑓後の若干時間に於ける变化が，たと光僅少では山つ

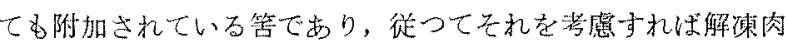
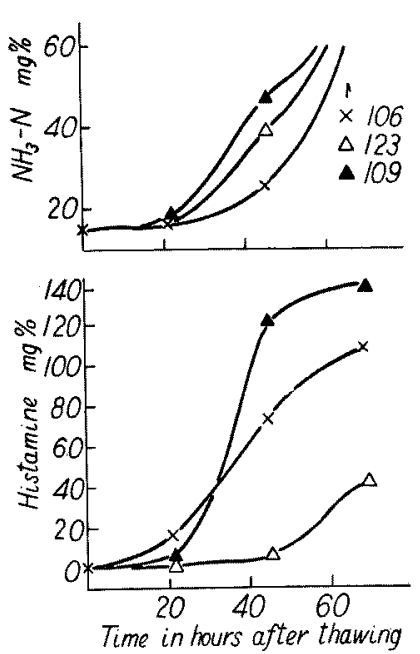

Fig. 5. Accerelation of histamine formation by the inoculation of spoiled fish muscle to the thawed muscle of round herring. $x$, unfrozen; $\triangle$, frozen and kept at $-10 \sim-16^{\circ} \mathrm{C}$ for 34 days; $\wedge$, at $-10 \sim-16^{\circ} \mathrm{C}$ for 34 days (inoculated).
の $\mathrm{Hm}$ 生成量は更少い事になるから でる。

\section{3. 解凍肉に腐敗肉を接種した場合 の変化}

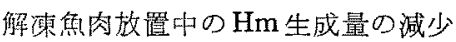
が，䂾結によつて自肉自身が变化した ためなのか，或いは谏結が Hmを生成 する細菌に何らかの影照を与光たため なのかを見るために，解凍肉以腐敗肉 の㤵濁液を接種してその後の放置中の 変化をしらべた。即b，B，C 室に 50 日間巅結脖蔵したサバ内について行つ た結果（Fig. 4）によると，Amいい

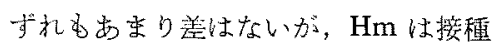
しない解棟肉で始ど生成されないの に, 接種したものは対照空(未凍肉)に 近い文はそれ以上の生成是を示した。 これらの傾向は B 室に34日間涑結得 咸したりルメイワシ肉についての結果 (Fig. 5) によると更に明睹で，接種し

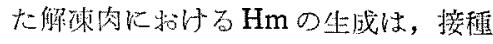
しないものよりも造かれ多く, 対照の 米柘肉のそれより多加つた。徒つ 
て, 魚肉中の $\mathrm{Hm}$ の生成に対し凁絬処理が阻㫪的なのは，凍絬が魚肉自身を变化させたためではなく，生

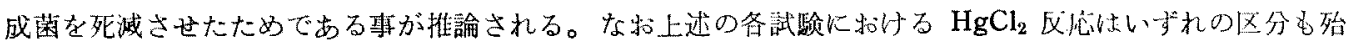
ぞ同様に变化した。

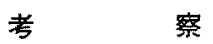

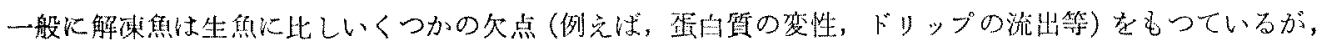
この実験の細䂙内についての結果を魚体そのままの場合に適用することが詐されるならば（少くも應敗に関 する従来の結果11からみると同じ傾向を示すものと思かれる)，Am 量， $\mathrm{HgCl}_{2}$ 反応の变化から見た保存性

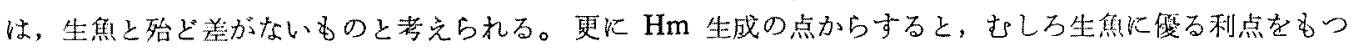

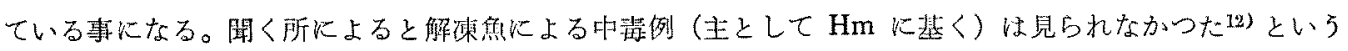
事である。

所でこの $\mathrm{Hm}$ 生成の抑制が如何なる作用によつたかについては，㶱結によつて魚肉自身が变化したが

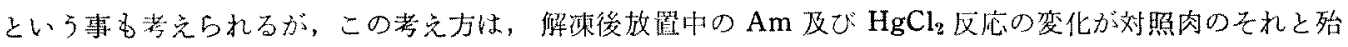

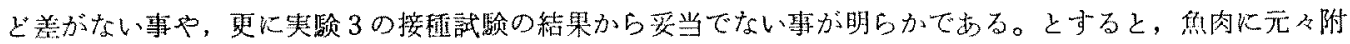

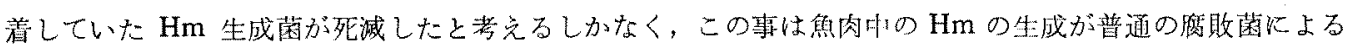
ものでなく若千の海水性細菌によるといら标等》の結果によつて強められる。今の所, $\mathrm{Hm}$ 生成菌の耐寒

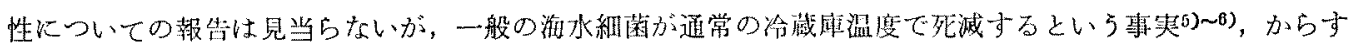
れば当然考兄られる事である(筆者らが予備的に行つ大試䮖でるこの事を琵付ける結果を得ている)。

要約

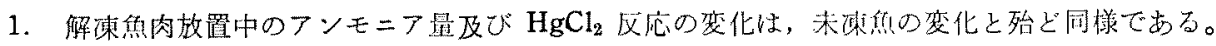

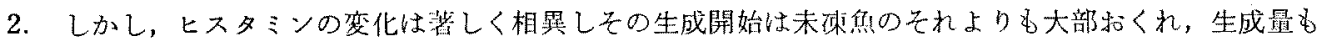
少なかつた。且つこれらの差異は谏結詝蔵の期間が長く，且つ温度が低くなるに従つて大きくなつた。

3. 解凍魚肉に腐敗魚肉を接種して放置した場合には, 未涑魚の場合と同様のとスタミン㱏の変化を示し た。

これらの事から生魚肉火附着していたヒスタミン生成菌が涷結によつて死减した事が考光られる。又解凍 魚の鮮度低下，腐敗によるヒスタミンに基く食品唯生上の危険性は一般に少ないるのと考光られる。

\section{文献}

1) E. H. Callow: Biochem. J., 19, 1 (1925).

2) 大谷武夫：水産学会報， 5,1928 .

3）加藤舞郎：“水産冷凍食品学” (1950), p. 384 .

4) R.H. Bedfurd: Contr. Can. Biol and Fish. N. S., 7, 433 438 (1933).

5) E. Hess: J. Biol. Bd. Can., 1, 95 108 (1934).

6) J. S. Kiser: Food Res., 7, 255 259 (1942).

7) M. Kimata and M. TanaKa: Mem. Res. Inst. Food. Sci. Kyoto Univ., No. 8, 7 16 (1954).

8) 太田冬雄：本誌，

9) — : - - 17, 309 312 (1951).

10）天野度之： 東海区水研報告, 1 (1950).

11) 清水 亘・日引重幸：本鿁，20，388～391 (1954).

12）天野度之：日本水産学会（東京, 1955，4）飞て発言. 